\title{
Bodily Contraction Arises with Dukkha: Embodied Learning to Foster Racial Healing
}

\author{
Brian J. Nichols
}

Citation: Nichols, Brian J. 2021.

Bodily Contraction Arises with

Dukkha: Embodied Learning to Foster Racial Healing. Religions 12: 1108. https://doi.org/10.3390/ rel12121108

Academic Editor: Beverley Foulks McGuire

Received: 3 November 2021 Accepted: 6 December 2021 Published: 16 December 2021

Publisher's Note: MDPI stays neutral with regard to jurisdictional claims in published maps and institutional affiliations.

Copyright: (C) 2021 by the author. Licensee MDPI, Basel, Switzerland. This article is an open access article distributed under the terms and conditions of the Creative Commons Attribution (CC BY) license (https:// creativecommons.org/licenses/by/ $4.0 /)$.
Department of Humanities, Mount Royal University, Calgary, AB T3E 6K6, Canada; bnichols@mtroyal.ca

\begin{abstract}
Black somatic therapist Resmaa Menakem has persuasively argued that racism exist in our bodies more than our heads and that racial healing requires learning to become mindful of our embodied states. The reason that racism remains prevalent despite decades of anti-racist education and the work of diversity and inclusion programs, according to Menakem, is that racist reactions that shun, harm, and kill black bodies are programmed into white, black, and police bodies. The first step in racial healing, from this point of view, is to shift the focus from cognitive solutions to an embodied solution, namely, embodied composure in the face of stressful situations that enables everyone to act more skillfully. Similar to how racial healing has been hampered by a misguided overemphasis on cognitive interventions, might our teaching be analogously encumbered by lack of attention to the bodies of teacher and students? In this article, I emphasize the value of cultivating body awareness in the classroom. I introduce an embodied exercise that teaches students to recognize embodied clues of the experience of $d u k k h a$, the first a rrya satya. Through such exercises, students take a step towards acting more skillfully and intentionally in stressful situations.
\end{abstract}

Keywords: meditation; embodiment; embodied learning; trauma; racism; Resmaa Menakem; contemplative pedagogy; mind-body dualism; racial healing; climate change; decolonization

\section{Introduction}

Black somatic therapist Resmaa Menakem (2017) has persuasively argued that racism exist in our bodies more than our heads and that racial healing requires learning to become mindful of our embodied states and reactions to other bodies. The reason that racism remains prevalent despite decades of anti-racist education and the work of diversity and inclusion programs, according to Menakem, is that racist reactions that shun, harm, and kill black bodies are programmed into white, black, and police bodies. The first step in racial healing, from this point of view, is to shift the focus from cognitive solutions to an embodied solution, namely, embodied composure in the face of stressful situations that enables everyone to act more skillfully. Similar to how racial healing has been hampered by a misguided overemphasis on cognitive interventions, might our teaching be analogously encumbered by lack of attention to the bodies of teacher and students? In this article I argue that the teaching of $d u k k h a$, the first ārya satya, can be enhanced and made more psychologically and socially relevant by guiding students in mindfulness of their embodied states. Such exercises can be understood as an application of contemplative pedagogy. The conclusion of this article will explore an assemblage of implications of the embodied turn and the overcoming of destructive dualistic ways of seeing through contemplative pedagogic exercises.

Scholars have increasingly integrated contemplative practices into their classrooms since the early 2000s. In 2013, Arthur Zajonc, president of the Mind and Life Institute, wrote of "a quiet pedagogical revolution" taking place since the late 1990s in higher education in the United States and around the world. This revolution was "contemplative pedagogy" (Zajonc 2013, p. 84). It makes use of "a wide range of educational methods that support the development of student attention, emotional balance, empathetic connection, 
compassion, and altruistic behavior, while also providing new pedagogical techniques that support creativity and the learning of course content" (ibid). It was a revolution because Cartesian mind-body dualism, privileging mind over body, and rational thought over intuition or feelings had dominated modern higher education since its inception. Simmer-Brown and Grace (2011, pp. xvi-xvii) have argued that higher education has largely abandoned the inner lives of students to the detriment of students and their ability to cultivate themselves intellectually, aesthetically, and ethically (pp. xvi-xvii). They hold that the incorporation of contemplative methods and meditation into education can "facilitate the interior accomplishments of self-knowledge and self-mastery" which are at the heart of a traditional liberal arts education (ibid). Their 2011 volume, Meditation and the Classroom, was a ground-breaking case for the potential of contemplative practices to have transformative educational impacts on students in line with the goals of secular universities. Their book helped me to design and teach my own contemplative studies course at my university since 2015. It has become wildly popular and is profoundly impactful on both the students and me. What I want to write about today is something that appears to be under-developed in the effort to bring contemplative practices into the classroom to enrich student self-knowledge or to introduce Buddhist concepts, namely, body awareness.

Several chapters in Meditation and the Classroom discuss the body as playing an important role in bringing contemplative practice into the classroom. Richard Brown (2011) notes how mindfulness of bodily sensations can be used as an important anchor to enhance teaching. Many others mention the importance of body awareness in moving beyond mind-body dualism in order to see how mind and body are bound together (Roth 2011; Lelwica 2011; Sarbacker 2011; Klein and Gleg 2011). We can build on these important observations about embodiment by drawing attention to embodied states in order to cultivate more understanding of how our bodies relate to emotional states and to our environment and to others.

Simmer-Brown (2011) examined this topic in her chapter titled "Emotional Learning: Recognizing Emotion in a Buddhism Course". At first glance, the topic seems similar or certainly related to my own concern with introducing the experience of $d u k k h a$, a sense of dissatisfactoriness, stress, anxiousness, or anxiety. However, the focus of Simmer-Brown's approach remains cognitively centered, while the approach I want to explore is more directly body-centered. Simmer-Brown explains how she gets students to investigate their emotions. She begins by "noting the texture of states of mind as they arise and pass away" and has students note "states of mind" (p. 230). She then guides students to notice "feeling tone" using the suggestions, "light or heavy" (ibid). She eventually asks students to describe experiences of strong emotions, such as anger, by describing how they feel physically, emotionally, and mentally (p. 232). The excerpts of student writings focus on cognitive descriptions, except for one that noted, "I could feel my whole body tense, my stomach especially" (p. 234). This is a reference to the type of bodily contraction that I seek to draw attention to as potentially having transformative power. In the analysis by Simmer-Brown, the physical sensations are generalized as the experience of pain, and the value of that experience is described by Simmer-Brown: "Mindfulness and awareness provide a direct way to see how intense emotions are painful, and when we experience pain directly, it is possible to drop our habitual patterns without forcing ourselves to do so" (p. 233). Thinking in terms of identifying and unlearning afflictive behavior is similar to what I am proposing, but my analysis goes deeper and argues that there is even more transformative potential of enhanced body awareness.

In general, scholars have emphasized cognitive gains that contribute to conventional educational goals such as improving attention, cognition and cognitive flexibility as well as gains in health, self understanding, and compassion (Zajonc 2013, p. 84; Barbezat and Bush 2013, p. 38). In other words, it has remained difficult to integrate the body and body awareness more fulsomely into the pedagogic endeavor. Resmaa Menakem criticizes the over-reliance on cognitive interventions for racial justice and emphasizes the need to work at the level of the body. Menakem bases this view on recent research 
into the nervous system, including studies in psychology and neuroscience. This research demonstrates how our bodies hold traumatic memories and the way in which our bodies respond immediately to perceived or real threats without cognitive intervention. As Menakem (2017) writes, "When it comes to safety, our thinking mind is third in line after our body and our lizard brain" (p. 6). If we place our hand on a hot stove top, for example, we immediately pull it away before our thinking mind knows what even happened. $\mathrm{N}$. Katherine Hayles (2017) brings additional insight to understanding how our bodies know without conscious awareness, in particular our stomachs and hearts, a knowing she terms "noncounscious cognition". Our bodies and our lizard brain keep us safe. It is also our bodies and lizard brain, Menakem argues, that are also most responsible for violence against black and brown bodies.

Menakem (2017) summarizes a set of beliefs or impressions that form a pervasive part of what he refers to as "white-body supremacy". These ideas include black bodies being dangerous, threatening, powerful, dirty, impervious to pain, hypersexual, needing to be managed and so on (p. 90). He then points out how once these ideas or impressions take root in a white or police body, that body will feel discomfort in the presence of a black body, especially a black stranger (p. 91). Menakem explains, "As a result, when many white American bodies encounter Black bodies, the white bodies automatically constrict, and their lizard brains go on high alert. Most forms of dialogue, diversity training, and other cognitive interventions are going to have little effect on this reflexive fear response, because the white body has been trained to respond in this noncognitive way" (ibid). This is why he proposes that the most effective intervention for black, white, and police bodies alike is mending personal and ancestral trauma through somatic therapy. As an initial step towards healing, Menakem first trains patients to notice bodily contraction and bodily relaxation in order to tune into their bodies and their autonomic nervous systems and how they respond to positive and negative situations. He writes, "As part of your healing from the trauma of white-bodied supremacy; you'll learn to tell when your body is open and when it is constricted; when it is settled and when it is activated; and where and when it is in pain or discomfort" (Menakem 2017, p. 34). It is this first step towards greater body awareness that I have begun to incorporate into teaching the first noble truth of Buddhism.

While Menakem has dialogued with Buddhist communities, he neither identifies as a Buddhist, nor does he advocate for explicitly Buddhist solutions. Nonetheless, there are striking parallels between his meditative exercises and Buddhist mindfulness practices. Additional parallels emerge between Menakem and Buddhist analyses in the connection between contracted or constricted states of the body and the presence of anger, greed or other afflictive states. Buddhist teacher Rob Burbea (1965-2020) wrote, "Whenever there is any grasping or aversion towards something, indeed whenever any hindrances are present, the mind is, to some degree or other, in a contracted state. It has, so to speak, been sucked into some perception, some object of consciousness, has shrunk and tightened around it. Generally we experience this contraction in the mind as an unpleasant state, as $d u k k h a^{\prime \prime}$ (Burbea 2014, p. 79). One way of understanding the connection between contraction and $d u k k h a$ is to realize that the mind habitually proliferates thoughts around an object of craving or aversion; this object becomes a focal point or an obsession, bringing tension, tightness, and pressure as one mentally circles around this object. This process includes what is termed rumination in psychological literature and is identified as a mental habit that plays a decisive role in afflictive states, in particular, depression (Watkins 2015, pp. 91-92). Burbea's (2014) description of these mind-body processes that give rise to negative states use terms and phrases that emphasize mind-body constriction. He writes of the "contraction of $d u k k h a$ " and speaks of "mental tightening" as well as "tightness in the body". It was my exposure to these ways of talking about $d u k k h a$, that began to suggest to me the relevance of incorporating Menakem into my Buddhism class.

One can observe such tension and tightening in one's own body when thinking of or viewing stressful content. We can also note a family of words that we commonly use to discuss stress, anxiety, difficulties, sadness or suffering, in a word, dukkha. These 
words constellate around contraction: knots/knotted, heavy, tangled, hard/hardened, ossified, concretized, stuck, rigid, bound, tied-up, dense, bottled up and so on-all pointing towards tightness, contraction, and heaviness. There is also a complementary and opposite constellation of words around the idea of healing, peace, and happiness. First and foremost is the word "relaxation", which indicates that loosening of tightness or tension or bonds. Other verbs include releasing, softening, unbinding, loosening, dissolving and opening. Nouns in this group include spaciousness, freedom, lightness and so on. Research on trauma in particular has discovered how trauma is transferred to the body and comes to inhabit the body as pain, tension, constriction or other conditions that impact the mindbody complex (van der Kolk 2015). More broadly speaking, the connection between our emotional states and our bodies is laid bare in such uses of language and presents an intriguing opportunity to explore how Buddhist forms of meditation can be adapted to cast a light on our embodied states which could support paths to healing and more skillful living.

In the Buddhist studies classroom, there are many opportunities to integrate contemplative exercises that cultivate body awareness. A natural place for the observation of bodily contraction arising in stressful or difficult situations is in the context of studying the first a rya satya or the noble truth of dukkha. It may be especially appropriate to revisit this material after introducing the teaching of dependent arising or interdependent arisal which can help students understand the experience as an example of the interdependent arisal of bodily states, emotion, and thought. Using an embodied contemplative practice to teach these concepts can bring them to life for students with lasting impact.

The meditation I have used in the classroom is adapted from an introductory "body practice" that Menakem (2017, pp. 32-34) includes in My Grandmother's Hands. Before we practice, I introduce the book and offer a summary of Menakem's central premises and goals. In the wake of the global Black Lives Matter protests, students are immediately engaged. We discuss the critique of cognitive approaches to diversity, equity, and inclusion initiatives and the need to address racial tension and conflict at the level of the body. I introduce the common finding of Menakem and Burbea that stress and anxiety arises in the body with states of contraction and constriction. Lastly, I introduce Menakem's argument that racially motivated violence is committed by one body against another and needs to be addressed at the level of the body and tell the students that the practice we are about to perform is an introductory practice to cultivate body awareness that can help one avoid acting unskillfully.

The practice involves observation of one's embodied response to two visualizations. The students are first asked to sit up straight in their chairs with their feet flat on the floor, pointing forward in a relaxed posture. They are asked to check in with their bodies and their breath. They are then asked to visualize a caring, supportive person walking towards them from a distance. As they approach the students are asked to notice how their bodies react. I read from Menakem, "This can be a friend, a relative, a neighbor, a partner, or a friendly acquaintance ... pay attention to what your body experiences. Does it relax or constrict? Does it want to move forward or backward? Does it want to reach out, or protect itself, or move in some other way?" (ibid: 33). After a minute, they are asked to clear their minds, breath and relax. Next, they are asked to visualize a person with whom some tension exists. Again, I read from Menakem, "Now visualize someone else you know, someone who is not particularly caring or supportive. This shouldn't be someone who is outright violent or dangerous, who has threatened you, or who is your sworn enemy. Instead, it might be a boss or coworker with whom you've had some friction, or a slightly standoffish neighbor, or perhaps a relative who disagrees with you on several political or social issues" (ibid). They are asked to visualize them walking towards them from a distance and as before, asked to notice how their bodies react using the same set of questions. Afterwards, they are asked to clear their minds and pay attention to their breath and relax as they return their attention to the classroom. 
When I lead this practice, it takes about six minutes, and immediately afterwards, I survey the students about their experiences and observations. For such open discussions to work well it is critical to have established a comfortable atmosphere for sharing and asking questions. I have found that students are generally eager to share their observations because they find the exercise interesting. On the whole, their responses have been in line with expectations. With the first visualization they report experiencing bodily comfort, relaxation, openness, and sensations of warmth. Some report having a desire to lean towards or reach out to the person. With the visualization of the standoffish or critical person the reports range from naming the emotions felt such as fear, anxiety or anger to noticing bodily tension or tightening in their stomach, chest, jaw or other areas. Some speak of their pulse quickening and breathing more quickly. One student wrote, "My heart rate increased and could feel it in my chest. I recall clenching my jaw and my body became more rigid. I also visualized myself running away from that person but tripping over obstacles, like I was trapped and couldn't get away." Some also share that they had similar responses to both prompts. I remind them that there are no right or wrong answers; students should be made to feel secure in sharing whatever they experienced.

I then remind them of the original context of this practice and how it is meant to be a means of developing self-awareness such that one can act more skillfully in stressful situations by learning to notice when one is activated and if appropriate, take steps to relax and breathe. I ask if it helps them understand how dukkha might be embodied and students overwhelmingly respond in the affirmative. Lastly, I ask them if they feel that the exercise helps them understand $d u k k h a$ as interdependently arisen with visualized or external cues and embodied states. This is a more advanced question and not all students are prepared to immediately respond. It may require revisiting the concept of interdependent arisal and the way that causes and conditions are thought to give rise to any given phenomena. Students typically respond with indications or nods of approval with regard to dukkha arising due to causes and conditions. In particular we discuss bodily factors involved with the experience of $d u k k h a$ and note bodily reactions such as tension and tightening and ways such reactions can be managed.

I conducted an online survey of one class to check their response to the exercise. Ninety-two percent of respondents (12/13) agreed with the statement, "This meditation/visualization helped me understand how dukkha might be embodied. How it may express itself in our bodies." One hundred percent of respondents agreed with the following statement, "This exercise/meditation gave me a greater appreciation of paying attention to my body/embodied states as part of my mental well being". Sixty-two percent agreed with "I feel I understand how exercises like this may play a role in racial healing". Students were also given space for any additional comments. One student volunteered appreciation for enhanced body-awareness, "I just found it very interesting how simple prompts could cause so many different feelings and sensations in my body in such a small amount of time". As experientially derived knowledge, it can be expected to be relatively better retained than content communicated through cognitive exploration alone.

Something that has emerged as a suggestion or even complaint from students centers around the sequence in which the visualizations occur. Students have suggested it would be better to perform the visualizations in reverse order, ending with the caring person, because they felt agitated after the second one and less prepared to return to class. I explain that I am following the recommended order and feel that it is designed to assist one in having more pronounced observations. It may also be helpful to remind students of the importance of getting out of their comfort zones for more novel forms of learning to take place. In response to this feedback I have, nonetheless, been more careful to add a minute or two for releasing tension following the second visualization, which also provides an example for how to deal with tension once it arises.

My experience in bringing this exercise into the classroom has been positive and encourages me to explore other ways we might cultivate greater body awareness among students. I have found students to be quickly on board with such goals. Most are familiar 
with "power poses" such as the Wonder Woman stance, with hands on hips and feet apart, which provides an instant boost to confidence. In introducing such practices, one may also speak about the many benefits of good posture. These perfectly secular examples of bodily posture impacting mood prepares students to accept the possibility of embodied states being linked with mood. By providing students an opportunity to grow in self-knowledge, as well as self-regulation or emotional regulation, this exercise cultivates what L. Dee Fink (2013, pp. 50-53) calls a significant learning experience.

\section{Conclusions}

As a way of concluding, I want to explore additional positive impacts from having students become more familiar with embodied states and how embodied states impact one's mental and emotional states as well as relations with others and the environment. In the context of intersecting crises of the twenty-first century, it behooves educators to prepare students for meeting those challenges. Those challenges are many and profound and include addressing white supremacy, the climate crisis, consumerism, authoritarianism, patriarchy, and legacies of colonialism. Universities are stepping up to address these challenges at institutional levels through a variety of programs and initiatives including climate commitments, EDI (equity, diversity, and inclusion) initiatives, decolonization efforts, and indigenization programs. In this conclusion I would like to consider how cultivating body awareness and mind-body integration may contribute to such initiatives, starting with a consideration of how they form part of trauma-informed pedagogy. Thus far, we have touched on two related areas of benefit, namely, the healing potential that comes from recognizing bodily states of contraction and learning ways to release the tension. Body awareness and enhanced self-regulation can help one to manage stress, anxiety, and potentially, assist with racial healing. While such goals may seem out of place in the classroom - after all, most professors are not qualified therapists-providing students with tools for emotional regulation and stress management can be seen as a requirement for a more trauma-informed approach to education.

In 2021, a special issue of the American Academy of Religion's (AAR) Religious Studies News' Spotlight on Teaching was dedicated to exploring trauma-informed pedagogies in religious studies classrooms (Tinklenberg 2021). With more than half of our students reporting having experienced a traumatic event, it becomes critical for educators to become more informed and proactive in exploring trauma-informed pedagogy (Stephens 2021, pp. 13-14). Darryl Stephens presents five core values guiding a trauma-informed approach: safety, trustworthiness, choice, collaboration, and empowerment (ibid: 16). These values represent starting points for designing assignments and positioning oneself as instructor. Other contributors go further by incorporating contemplative embodied forms of practice in their trauma-informed pedagogy. Leah Thomas (2021) introduces body awareness exercises in the context of addressing race in the classroom building on the work of Menakem and somatic therapy. Yohana Junker (2021) combines art, breathing, and meditation to aid students in body awareness and healing based on Paulo Freire's Pedagogy of the Heart and Menakem. Judging from educators known to be cultivating body awareness and their reference to Menakem, it should be clear to readers that a great starting point for exploring a trauma-informed lens and the pedagogic potential of embodied practices is $M y$ Grandmother's Hands.

While helping students process trauma, including racialized trauma, through enhanced body awareness is well supported by the sources above, I want to expand this discussion further by exploring the intersections between racialized trauma, the climate crisis, and mind-body dualism. I increasingly feel that educators must find ways to address the climate crisis in our classrooms given the urgency required to respond effectively to what bioethicist and past AAR President Laurie Zoloth $(2016$, p. 5) has aptly called the "moral imperative of our time". The question I want to first explore is: Can we address the climate crisis without addressing white supremacy? Not long ago, I was one of the many climate activists who wrongly thought that the urgency of the climate crisis demanded we 
confront it head on to halt the release of heat-trapping gases. Everything else (i.e., other issues of social justice), I reasoned, should be placed on hold in order to address this as the highest priority. My thinking began to shift with the help of an article by Zen priest and senior scientist with the Environmental Defense fund Kritee Kanko (2020), who argues that white supremacy is at the heart of the climate crisis. Claiming that white supremacy may be seen as the "mother of climate crisis," Kanko's approach is to see White-European ideology as driving the colonial exploitation and oppression of people of color around the world and the destruction of ecosystems in pursuit of wealth and resources. These ways of knowing and being captured by the term white supremacy are thus behind the modern industrialization and extractivism that has led to the climate crisis. Kanko also points out the ways of knowing and being best suited to living in sustainable relationship with the environment are in found among Indigenous communities and other communities of color. Using Thich Nhat Hanh's term "interbeing" as a model for healthy relationship between humans and nature, she writes,

"White supremacy (sometimes called European Supremacy) has systematically harmed cultures of black, indigenous and other people of color (BIPOC): the very cultures who knew how to honor the truth of "Interbeing" in their daily lives and how to live in harmony with land and all beings in an ecosystem. When humans forget how to honor interdependence and Interbeing, they succumb to unsustainable and traumatizing hyper-individualism (i.e., I only need to take care of myself)" (Kanko 2020).

Others have also argued for the need to center the voices and experience of black, Indigenous, and other people of color in discussions of climate action. An article by Hop Hopkins (2020) focuses on the central role of sacrifice zones based on racially segregated disposable communities in furthering the climate crisis. Such sacrifice zones, which expose populations to disease causing toxins and other pollutants, are well known to be based in communities of color as well as low-income areas. This pervasive reality is captured in the phrase "environmental racism" and has been found to exist around the world (Pulido 2017; Johansen 2020). Black, Indigenous, and other people of color from the global South, in particular, have suffered the most from colonialism and racism and stand to lose the most, most quickly, as the climate changes. Links between the climate crisis and colonial history and perduring racial bigotry are evident. Links between racism and the climate crisis have been highlighted by others including ecopsychologist Zhiwa Woodbury (2020) and author Rebecca Solnit (2019). If Menakem is right and racial healing begins with understanding our embodied responses to stress, incorporating embodied-learning exercises into our classrooms may serve as a first step in that direction as well as advance us towards acting on climate.

Lastly, I want to explore further this link between colonial ideology and racism. It may be helpful to go back to the oft cited origin of the rift in Euro-American culture between body and mind, the meditations of Descartes (1596-1650), who sought to provide firm footing for the development of philosophy and science by proposing cogito ergo sum (I think, therefore I am). Cartesian dualism, as it has come to be known, provided the basis for scientific understandings of the world which treated the earth as dead and inert, to be conquered, subdued, studied, and mastered. These ideas became woven into colonial projects supported by religious ideas of domination of nature and mastery over nonhuman animals and non-Christian populations. Thus, colonialism and extractivism and the violence they have perpetrated against ecosystems and human populations is based on a set of views and values that degrade the natural world and other non-European populations that are perceived to be living closer to the land. The grammar of this world view may have been in the Bible, but it was given modern cache by Cartesian dualism, which severed the mind from the body and valued rational thought over embodied feelings. These views were combined with patriarchal ideology to value men as rational over women who were seen as more enslaved to their bodies and therefore less rational. These views were combined with Darwinism to propose that rational Europeans were more evolved 
than the more land-based Indigenous peoples around the world (Ansell 2013, pp. 145-47). Again, these sexist and racist projects were supported by Cartesian dualism that elevated rational mind over the feeling body. If mind-body dualism is a critical component of colonial violence, then overcoming that dualism is a key to entering a new era of healing, reconciliation, restitution, and right relation. Joanna Macy has termed such a revolution, "the Great Turning."

Joanna Macy's life work has been to counter dualistic worldviews of separation that are seen to lead to a lack of respect for the natural world and an ensuing ecological crises. As stated in Coming Back to Life, a central tenet is, "The global crisis is at root a crisis in perception. There is no technological fix" (Macy and Brown 2014, p. 138). The change in perception that is needed according to Macy is understanding our intimate connection with the world as expressed in non-dualistic understanding of self and other, an understanding of the intimate connections between humans and the non-human world. Many contemplative studies educators are on the same page when it comes to advancing education in more holistic directions (e.g., Coburn 2013). These alternative relationships and perspectives are elaborated in Macy's (2021) World as Lover, World as Self. The non-dual perspectives presented as resources by Macy include the "interbeing" between humans, non-human animals and the natural world advocated by Kanko, as well as non-dual traditions in Hinduism, Indigenous traditions, and emerging perspectives in systems theory and deep ecology.

In summation, those of us teaching in the early decades of the twenty-first century must realize the unprecedented nature of the intersecting crises we face along with the students we teach. To live and work in consonance with our heart and mind requires us to find ways to prepare students for the future they want. Becoming more aware of the integration of mind and body holds the potential to make students better attuned to their relationship with the natural world, which is of paramount importance as a motivation to protect it in addition to being a first step towards racial healing. The humble claim is that experientially guiding students beyond mind-body dualism through mindfully based contemplative practices is a means of taking an important step towards the solving of these many problems. As unlikely as it may seem, projects of decolonization, indigenization, confronting white supremacy, and addressing the climate crisis may all be advanced by enhancing body awareness, mind and body integration, and attendant repairing of relationships.

Funding: This research received no external funding.

Institutional Review Board Statement: Not applicable.

Informed Consent Statement: Informed consent was obtained from all subjects in the study.

Data Availability Statement: Data available on request due to privacy.

Conflicts of Interest: The author declares no conflict of interest.

\section{References}

Ansell, Amy. 2013. Race and Ethnicity: The Key Concepts. London: Taylor \& Francis Group. Ebook Central.

Barbezat, Daniel P., and Mirabai Bush, eds. 2013. Contemplative Practices in Higher Education: Powerful Methods to Transform Teaching and Learning. Somerset: John Wiley \& Sons.

Brown, Richard. 2011. The Mindful Teacher as the Foundation of Contemplative Pedagogy. In Meditation and the Classroom. Edited by Judith Simmer-Brown and Fran Grace. New York: SUNY Press, pp. 75-83.

Burbea, Rob. 2014. Seeing That Frees: Meditations on Emptiness and Dependent Arising. Ogwell: Hermes Amāra Publications.

Coburn, Thomas. 2013. Peak Oil, Peak Water, Peak Education. In Contemplative Studies in Higher Education: New Directions for Teaching and Learning. Edited by Linda A Sanders. Somerset: John Wiley \& Sons, pp. 3-11.

Fink, L. Dee. 2013. Creating Significant Learning Experiences: An Integrated Approach to Designing College Courses. San Francisco: Jossey-Bass.

Hayles, N. Katherine. 2017. Unthought: The Power of the Cognitive Nonconscious. Chicago: University of Chicago Press. 
Hopkins, Hop. 2020. Racism Is Killing the Planet: The Ideology of White Supremacy Leads the Way toward Disposable People and a Disposable Natural World. Sierra: The Magazine of the Sierra Club, June 8. Available online: https:/ /www.sierraclub.org/sierra/ racism-killing-planet (accessed on 20 October 2021).

Johansen, Bruce E. 2020. Environmental Racism in the United States and Canada: Seeking Justice and Sustainability. Santa Barbara: ABC-CLIO.

Junker, Yohana Agra. 2021. Breathing | Being | Praying Meditations: The Generative Possibilities of the Arts. In Spotlight on Teaching. Edited by Jessica Tinklenberg. Atlanta: American Academy of Religion, pp. 57-60.

Kanko, Kritee. 2020. White Supremacy=Mother of Climate Crisis. Boundless in Motion: Zen Meditation, Grief-Rituals $\mathcal{E}$ Strategic Activism, March 5. Available online: http:/ / boundlessinmotion.org/white-supremacy-mother-of-climate-crisis/ (accessed on 20 October 2021).

Klein, Anne C., and Ann Gleg. 2011. Contemplative Inquiry: Beyond the Disembodied Subject. In Meditation and the Classroom. Edited by Judith Simmer-Brown and Fran Grace. New York: SUNY Press, pp. 187-93.

Lelwica, Michelle. 2011. Embodied Contemplative Learning: Akido as a Case Study. In Meditation and the Classroom. Edited by Judith Simmer-Brown and Fran Grace. New York: SUNY Press, pp. 141-46.

Macy, Joanna. 2021. World as Lover, World as Self: Courage for Global Justice and Planetary Awakening, 30th Anniversary ed. Berkeley: Parallax Press.

Macy, Joanna, and Molly Brown. 2014. Coming Back to Life: The Updated Guide to the Work That Reconnects. Gabriola Island: New Society Publishers.

Menakem, Resmaa. 2017. My Grandmother's Hands: Racialized Trauma and the Pathway to Mending our Hearts and Bodies. Las Vegas: Central Recovery Press.

Pulido, Laua. 2017. Geographies of race and ethnicity II: Environmental racism, racial capitalism and state-sanctioned violence. Progress in Human Geography 41: 524-33. [CrossRef]

Roth, Harold D. 2011. Contemplative Studies: Can It Flourish in the Religious Studies Classroom. In Meditation and the Classroom. Edited by Judith Simmer-Brown and Fran Grace. New York: SUNY Press, pp. 23-37.

Sarbacker, Stuart Ray. 2011. Reflections on Theory and Practice: The Case of Modern Yoga. In Meditation and the Classroom. Edited by Judith Simmer-Brown and Fran Grace. New York: SUNY Press, pp. 147-53.

Simmer-Brown, Judith. 2011. Emotional Learning: Re-cognizing Emotion and Thought in a Buddhism Course. In Meditation and the Classroom. Edited by Judith Simmer-Brown and Fran Grace. New York: SUNY Press, pp. 229-35.

Simmer-Brown, Judith, and Fran Grace, eds. 2011. Meditation and the Classroom. New York: SUNY Press.

Solnit, Rebecca. 2019. Why Climate Action Is the Antithesis of White Supremacy. The Guardian, March 19. Available online: https:/ / www.theguardian.com/commentisfree/2019/mar/19/why-youll-never-meet-a-white-supremacist-who-cares-aboutclimate-change (accessed on 20 October 2021).

Stephens, Darryl W. 2021. What is Trauma? What is a Trauma-Informed Approach? In Spotlight on Teaching. Edited by Jessica Tinklenberg. Atlanta: American Academy of Religion, pp. 9-18.

Thomas, Leah. 2021. Addressing Race in the Classroom: A Trauma-Informed Communal Embodied Practice. In Religious Studies News, Spotlight on Teaching. Edited by Jessica Tinklenberg. Atlanta: American Academy of Religion, pp. 23-28.

Tinklenberg, Jessica, ed. 2021. Trauma-Informed Pedagogies in the Religious Studies Classroom. In Religious Studies News, Spotlight on Teaching. Atlanta: American Academy of Religion, March.

van der Kolk, Bessel. 2015. The Body Keeps the Score. New York: Penguin Books.

Watkins, Edward R. 2015. Mindfulness in the Context of Processing Mode Theory. In Handbook of Mindfulness: Theory, Research, and Practice. Edited by Kirk Warren Brown, J. David Creswell and Richard M. Ryan. New York: Guilford Publications, pp. 90-111.

Woodbury, Zhiwa. 2020. Is Racism the REAL Reason for Our Climate Inaction? Zhiwa Woodbury, June 14. Available online: https: // thubtenzhiwa.medium.com/is-racism-the-real-reason-for-our-climate-inaction-717b8bfcd047 (accessed on 20 October 2021).

Zajonc, Arthur. 2013. Contemplative Pedagogy: A Quiet Revolution in Higher Education. In Contemplative Studies in Higher Education: New Directions for Teaching and Learning. Edited by Linda A Sanders. Somerset: John Wiley \& Sons, pp. 83-94.

Zoloth, Laurie. 2016. 2014 AAR Presidential Address: Interrupting Your Life: An Ethics for the Coming Storm. Journal of the American Academy of Religion 84: 3-24. [CrossRef] 